\title{
ÜBER DEN
}

\section{LIBER DE OFFICIO PROCONSULIS.}

vON

\section{ADOLF FRIEDRICH RUDORFF.}

AUS DEN ABHANDLUNGEN DER KÖNIGL. AKADEMIE DER WISSENSCHAFTEN

ZU BERLIN 1865.

BERLIN.

GEDRUCKT IN DER BUCHDRUCKEREI DER KÖNIGL. AKADEMIE DER WISSENSCHAFTEN.

1866.

IN COMMISSION BEI F. DOMMLER'B VERLAGS-BUCHHANDLUNG.

HARKWITZ UND GOSSMANN. 
